\title{
Early Results of Fibular Osteotomy for Treatment of Medial Compartment Osteoarthritis
}

Adnan Elsebaiy ${ }^{(1)}$, Hesham Safwat ${ }^{(1)}$, Ahmed Abdel Rahman Ashiry ${ }^{(2)}$

Professor at Department of Orthopaedic Surgery, Al-Azhar Faculty of Medicine, Cairo (1)

Resident Doctor at Department of Orthopaedic Surgery, El-Fayoum General Hospital (2)

Corresponding Author: Ahmed Abd Elrahman Ashiry Mob: 01009951568, email: a_elashiry87@yahoo.com

\section{ABSTRACT}

Background: knee O.A was treated by total knee arthroplasty but it is new procedure still under trial for treatment of medial compartment knee O.A. Objective: To assess the early results of proximal fibular osteotomy as a new surgery for pain relief and improvement of functions of the knee in patients with medial compartment OA.

Patients and methods: From July 2016 to September 2018, 10 patients who underwent proximal fibular osteotomy for medial compartment osteoarthritis. Preoperative and postoperative knee society score (KSS) and visual analogue scale (VAS) were obtained to assess knee functions and pain

Results: median knee society score (KSS) show improvement postoperatively from 83 to 105 and visual analogue scale (VAS) decreased postoperatively from 8.5 to 4.

Conclusions: This study shows that proximal fibular osteotomy (PFO), a new surgery, can effectively relieves pain and improves knee function in patients with medial compartment osteoarthritis.

Key words: Early results, Proximal fibular osteotomy, Medial compartment knee O.A.

\section{INTRODUCTION}

Osteoarthritis (OA) of the knee is one of the most common progressive diseases that has an increased incidence and prevalence in people over the age of 40 years. Around $10 \%$ of all people older than 60 years of age have radiological signs of knee O.A, and about half of those complain of clinical symptoms of musculoskeletal diseases. OA is common cause of disability and limitation of daily activities and work ${ }^{(1)}$.

Genu varus deformities, characterized by a mechanical femoro-tibial axis less than $180^{\circ}$ on full leg standing antro-posterior (AP) radiograph and narrow joint space medially, are common in patients with knee OA and affect $74 \%$ of patients with idiopathic OA. It was reported, that the medial compartment of the knee bears around $60 \%$ to 80 of the load in healthy knees. It is believed that the load is distributed along the mechanical axis, which is generally medial to the center of the knee $(2,3)$.

High tibial osteotomy and total knee arthroplasty are the two methods used for treating knee OA. High tibial osteotomy is a technically demanding procedure and may result in complications, including neurovascular injury, iatrogenic fracture, and nonunion ${ }^{(4,5)}$. Total knee arthroplasty (TKA) can relieve pain, correct lower limb alignment, and improve function. However, for younger, active patients or patients with moderate $\mathrm{OA}$, it may not be the treatment of choice ${ }^{(6)}$.

In 2015, Zhang et al. reported that proximal fibular osteotomy (PFO) improves joint function and relieves pain in human knee $\mathrm{OA}^{(7)}$. This new surgery is safe, simple and affordable. Pain relief occurs after surgery in almost all patients. PFO may replace or delay TKA in a subpopulation of patients with medial compartment knee osteoarthritis. In the present study, we

evaluated the early results of PFO according to visual analog score (VAS) and Knee society score (KSS).

\section{PATIENTS AND METHODS}

From July 2016 to September 2018, 10 patients who underwent PFO at El- Fayoum and Al-Azhar University Hospital were followed retrospectively. Their sociodemographic data are shown in table 1.

Inclusion criteria: (i) Medial compartment knee OA with varus knees (ii) Good lateral joint space in weight bearing films (iii) Patient's age above 45 (iv) Severe pain for the patient to request for surgical intervention.

Exclusion criteria: (i) Tricompartmental arthritis (ii) Post traumatic OA (iii) Fixed flexion deformity (iv) Very obese patient (v) Bone on bone in standing AP X-ray.

Table (1): Sociodemographic data of patients

\begin{tabular}{|c|c|c|}
\hline Variable & Mean & SD \\
\hline Age & 62.2 & 1.8 \\
\hline Variable & $\mathbf{N}$ & $\%$ \\
\hline \multicolumn{3}{|l|}{ Sex } \\
\hline Female & 7 & $70.0 \%$ \\
\hline Male & 3 & $30.0 \%$ \\
\hline
\end{tabular}

Surgical technique: Under spinal anesthesia; patients were supine on a standard radiolucent orthopedic table. The lower limb tourniquet was inflated. The fibular head was identified to avoid injury of the common peroneal nerve. A lateral incision 3 to $5 \mathrm{~cm}$ was made at the proximal third of the fibula. The fascia was opened in line with the septum between the peroneus and soleus, the 
muscles were separated, and the fibula was exposed. A 2$\mathrm{cm}$ section of the fibula was cut 6 to $10 \mathrm{~cm}$ below the fibular head with the use of a saw. After resection, irrigation with a normal saline, the muscles, fascia, and skin were sutured separately ${ }^{(7)}$.

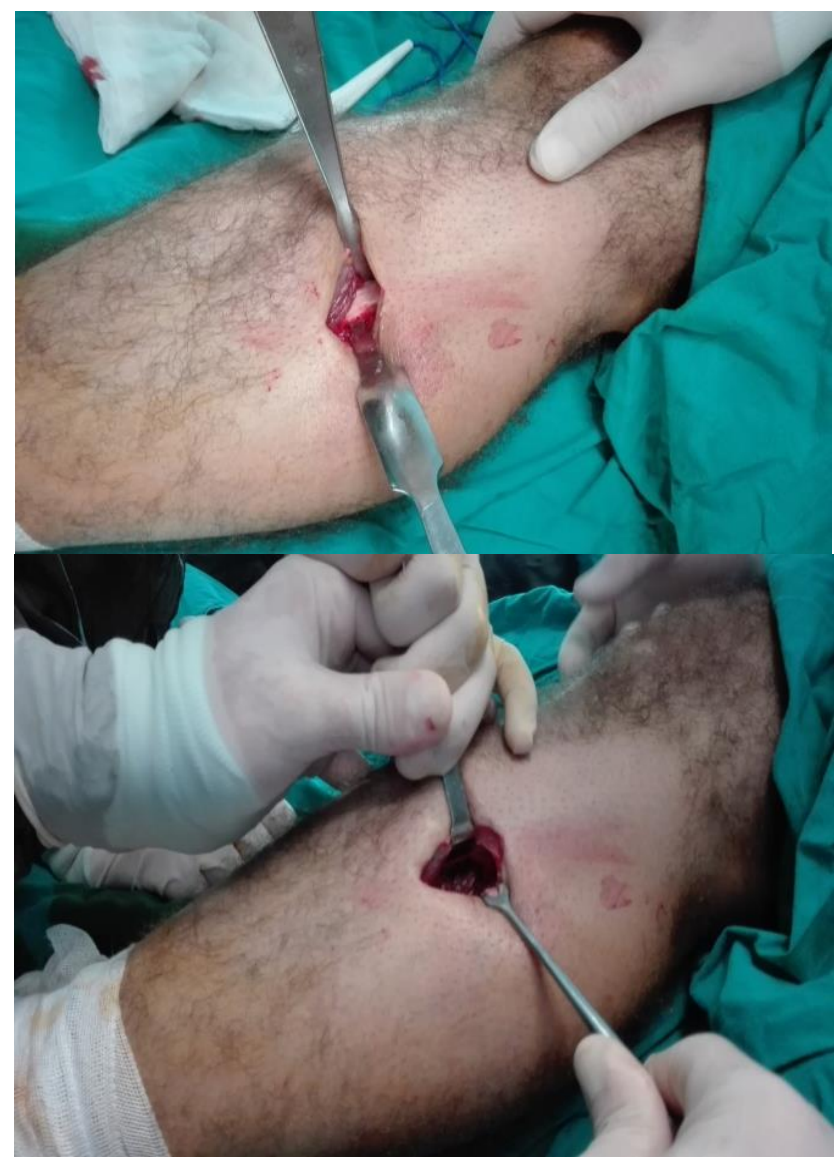

Figure 1 the fibular segment before and after osteotomyFree mobilization and weight bearing were allowed postoperatively. Knee pain was assessed using a visual analogue scale (VAS). Knee ambulation activities were recorded using the knee and function subscores of the American Knee Society score (KSS) preoperatively and postoperatively.

\section{Ethical approval:}

The study was approved by the Ethics Board of Al-Azhar University and an informed written consent was taken from each participant in the study.

\section{Statistical analysis of data:}

The collected data was organized, tabulated and statistically analyzed using SPSS software statistical computer package version 22 (SPSS Inc, USA). For quantitative data, the mean and standard deviation (SD) or median and range were calculated. Wilcoxon Signed Rank test was used in comparing between each two readings of the study parameters (before, two and four months after intervention). For qualitative data the number and percent distribution was calculated. For interpretation of results of tests of significance, significance was adopted at $\mathrm{P} \leq 0.05$.
Results: This study shows the early results of proximal fibular osteotomy for treatment of medial compartment knee OA. The knee function was assessed two and four months postoperatively by using of KSS and VAS.

Knee score: ranged from 24 to 55 preoperatively with median 43.5 and increased two months postoperatively from 40 to 67 with median 55 .

Function score: ranged from 20 to 60 preoperatively with median 35 and increased two months postoperatively from 30 to 70 with median 50 .

Knee society score: is the sum of knee score and function score which in totally show improvement from preoperative median 83 to 105 postoperatively.

Table (2): KSS preoperative and 2, 4 months postoperative

\begin{tabular}{|c|c|c|c|}
\hline & Median & nimum & eximum \\
\hline Preoperative & 83 & 44 & 115 \\
\hline After 2 months & 105 & 70 & 135 \\
\hline After 4 months & 105 & 50 & 135 \\
\hline \multicolumn{4}{|l|}{ P-value } \\
\hline $\begin{array}{l}\text { Preoperative vs. } \\
\text { After } 2 \text { months }\end{array}$ & \multicolumn{3}{|c|}{ 0.005* } \\
\hline $\begin{array}{l}\text { Preoperative vs. } \\
\text { After } 4 \text { months }\end{array}$ & \multicolumn{3}{|c|}{$0.007 *$} \\
\hline $\begin{array}{l}\text { After } 2 \text { months vs. } \\
\text { After } 4 \text { months }\end{array}$ & \multicolumn{3}{|c|}{0.317} \\
\hline
\end{tabular}

*Significant

Visual analogue scale (VAS): is a self-report measure by patient himself which ranged preoperatively from 7 to 10 and after two months postoperatively from 3 to 5 and after four months from 3 to 7 .

Table (3): VAS preoperative and 2, 4 months postoperative

\begin{tabular}{|l|c|c|c||}
\hline & Median & Minimum & Maximum \\
\hline Preoperative & 8.5 & 7 & 10 \\
\hline After 2 months & 4 & 3 & 5 \\
\hline After 4 months & 4 & 3 & 7 \\
\hline P-value \\
\hline $\begin{array}{l}\text { Preoperative vs. } \\
\text { After 2 months }\end{array}$ & \multicolumn{3}{|l|}{$\mathbf{0 . 0 0 4 *}$} \\
\hline $\begin{array}{l}\text { Preoperative vs. } \\
\text { After 4 months }\end{array}$ & \multicolumn{3}{|l}{$\mathbf{0 . 0 0 5 *}$} \\
\hline $\begin{array}{l}\text { After 2 months } \\
\text { vs. After 4 } \\
\text { months }\end{array}$ & & 0.257 \\
\hline
\end{tabular}

*Significant

Complications: three patients had numbness of the foot and four patients had EHLP. One of the four patients showed improvement of the big toes extension 
through four months follow up while all patients with numbness showed improvement during follow up.

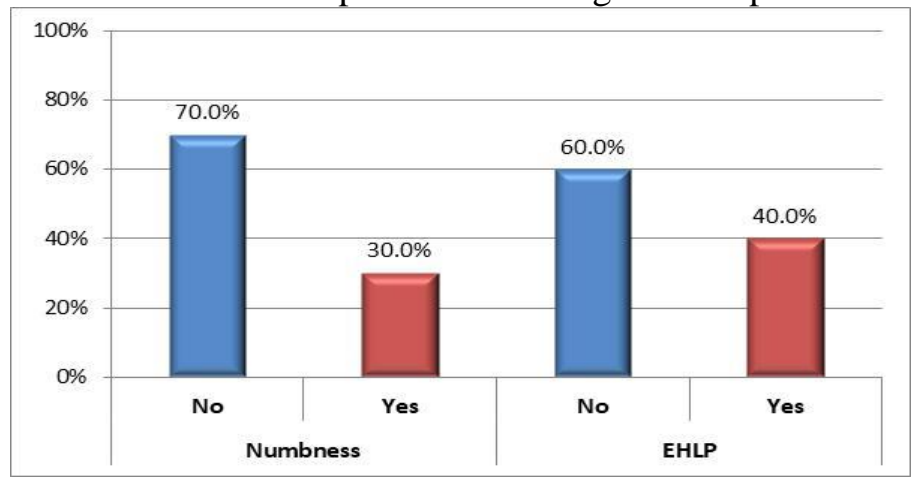

Figure 2 complications of the surgery

\section{DISCUSSION}

Knee osteoarthritis is the most common joint disease, and it causes severe pain and disability. TKA very effectively relieves pain and improves functions in patients with late stage knee osteoarthritis. However, TKA is complex, expensive and some patients need a second revision ${ }^{(7,8)}$. High tibial osteotomy (HTO) was the surgical treatment of choice for young patients with osteoarthritis of the medial compartment of the knee, and it was aiming to realignment and delaying the time until TKA is required ${ }^{(9,10)}$. However, HTO has some disadvantages, as risks of nonunion or delayed union, a delayed weight bearing, peroneal nerve injury and wound infection $^{(11,12)}$.

In this study we did PFO as a new surgery for patients with knee OA to relieve pain and improve knee function. Most patients had significant improvement after PFO and some patients reported no pain in follow-up. Postoperative activities were also obviously improved when compared with

Zong-You et al. from January 1996 to April 2012, a total of 156 patients with medial compartment OA were treated by proximal fibular osteotomy in the authors' hospital. KSS increased by 47.3 points in the final analysis. According to VAS scores, pain levels decreased significantly from severe to mild. In this study, $4(3.6 \%)$ patients reported numbness in the ipsilateral lower leg due to common peroneal nerve palsy and superficial peroneal nerve injury ${ }^{(7)}$.

Xiaohu et al. From January 2015 to May 2015, 47 patients who underwent proximal fibular osteotomy for medial compartment osteoarthritis. One of 47 patients who underwent PFO was lost to follow-up, leaving 46 patients who were followed for a minimum of 12 months. medial pain relief was observed in all patients after PFO. The mean visual analogue scale scores significantly decreased from 8.02_1.50 preoperatively to $2.74 \_2.34$ postoperatively. Preoperatively, the mean knee and function subscores of the American Knee Society score were 44.41_8.90 and 41.24_13.48, respectively. Postoperatively, they significantly improved to 69.02_11.12 and 67.63_13.65, respectively ${ }^{(13)}$.

\section{CONCLUSION}

In conclusion, we recommend proximal fibular osteotomy for medial compartment knee O.A. as it is minimally invasive, simple, safe, fast and affordable procedure especially in young patient.

\section{REFERENCES}

1. Merx H, Dreinhöfer K, Günther K(2007): Socioeconomic relevance of osteoarthritis in Germany. Zeitschrift fur Orthopadie und Unfallchirurgie, 145(4): 421-429.

2. Jackson D, Simon T, Aberman H(2001): Symptomatic articular cartilage degeneration: the impact in the new millennium. Clinical Orthopaedics and Related Research (1976-2007).391:S14-S25.

3. Buckwalter J, Saltzman C, Brown T (2004): The impact of osteoarthritis: implications for research. Clinical Orthopaedics and Related Research (1976-2007). 427:S6-S15.

4. Wu L, Hahne H, Hassenpflug T (2004): A long-term followup study of high tibial osteotomy for medial compartment osteoarthrosis. Chinese journal of traumatology= Zhonghua chuang shang za zhi., 7(6): 348-353.

5. Sprenger $\mathbf{T}$, Doerzbacher $\mathbf{J}$ (2003): Tibial osteotomy for the treatment of varus gonarthrosis: survival and failure analysis to twenty-two years. JBJS., 85(3): 469-474.

6. Schnurr C, Jarrous M, Güdden I, Eysel P, König D(2013): Pre-operative arthritis severity as a predictor for total knee arthroplasty patients' satisfaction. International orthopaedics, 37(7): 1257-1261.

7. Zhang Y(2015): Innovations in orthopedics and traumatology in China. Chinese medical journal, 38(12):e1110-e1114

8. Burnett R, Bourne R(2003): Indications for patellar resurfacing in total knee arthroplasty. JBJS., 85(4): 728-745.

9. Duivenvoorden T, Brouwer R, Baan A, Bos P, Reijman M, Bierma-Zeinstra S, Verhaar J(2014): Comparison of closing-wedge and opening-wedge high tibial osteotomy for medial compartment osteoarthritis of the knee: a randomized controlled trial with a six-year follow-up. JBJS., 96(17): 14251432.

10. LaPrade R, Spiridonov S, Nystrom L, Jansson K(2012): Prospective outcomes of young and middle-aged adults with medial compartment osteoarthritis treated with a proximal tibial opening wedge osteotomy. Arthroscopy: The Journal of Arthroscopic \& Related Surgery, 28(3): 354-364.

11. Sprenger T, Doerzbacher J(2003):Tibial osteotomy for the treatment of varus gonarthrosis: survival and failure analysis to twenty-two years. JBJS., 85(3): 469-474.

12. W-Dahl A, Robertsson O, Lidgren L(2010): Surgery for knee osteoarthritis in younger patients: a Swedish Register Study. Acta orthopaedica, 81(2): 161-164.

13. Wang X, Wei L, Zhao B, Duan Z, Wei $X(2017)$ : Proximal fibular osteotomy: a new surgery for pain relief and improvement of joint function in patients with knee osteoarthritis. Journal of International Medical Research, 45(1): 282-289. 